\title{
Multiple congenital anomalies in a Korean native calf (Bos taurus coreanae)
}

\author{
Mohammad Rafiqul Islam ${ }^{1}$, Yoon-Seok Roh ${ }^{1}$, Ara Cho', Heejin Park ${ }^{1}$, Soo Young Heo ${ }^{1}$, \\ Kichang Lee ${ }^{1}$, Han Kyung Lee ${ }^{2}$, Chae Woong Lim', Bumseok Kim ${ }^{1, *}$ \\ ${ }^{1}$ Bio-safety Research Institute and College of Veterinary Medicine, Chonbuk National University, Jeonju 561-756, Korea \\ ${ }^{2}$ Happy Veterinary Hospital, Kimje 576-806, Korea
}

(Accepted: December 27, 2010)

\begin{abstract}
Supernumerary ectopic limb(s) (SEL) is a congenital anomaly defined as the presence of accessory $\operatorname{limb}(\mathrm{s})$ attached to various body regions. This paper describes a case of SEL with ectopic lung and ectopia cordis in a newborn calf, based on macroscopic, microscopic and radiographic findings. External features of multiple congenital anomalies included an ectopic lung growing over the middle of the backbone and covered with normal haired skin. Ectopia cordis was found in the abdominal cavity and attached to the liver. Two extra abnormal limbs originated separately from within the ectopic lung. Most of the abdominal organs were exposed to the outside through the opened abdominal cavity. Microscopically the ectopic lung tissue had edema in the connective tissue around the bronchus and artery. Changes in other organs included congestion of the renal medulla, infiltration of inflammatory cells (lymphocytes and eosinophils) around the hepatic portal tract, and edema surrounding blood vessels and neurons in the brain. The rudimentary humerus of the forelimb was attached to the thoracic spine, as viewed radiographically. The hindlimb was consisted of an irregularly shaped femur, short tibia and fibula, two tarsal bones, one metatarsal bone, and three phalanges. This is the first description of congenital anomalies involving the SEL, ectopic lung and ectopia cordis in a calf.
\end{abstract}

Keywords : calf, ectopia cordis, edema, limb, lung

\section{Introduction}

A congenital anomaly is defined as an abnormality of structure or function present at birth [13]. Multiple congenital anomalies often occur together, as an abnormality of one part of the body often leads directly to the malformation of other body parts [4]. A number of congenital anomalies are known to occur in domestic cattle [16]. Supernumerary ectopic $\operatorname{limb}(\mathrm{s})$ (SEL) is a congenital anomaly defined as the presence of an accessory $\operatorname{limb}(\mathrm{s})$ attached to one of various body regions. Heterotopic polymelia involves one or two SELs and is classified as cephalomelia, notomelia, thoracomelia, or pygomelia [11]. Leipold and Dennis [11] reported the proportions of congenital defects in cattle involving the musculoskeletal system $(24 \%$ of defects), respiratory and alimentary tracts (13\%), central nervous system (22\%), abdominal wall $(9 \%)$, urogenital system (4\%), cardiovascular system (3\%), skin $(2 \%)$, and others $(4 \%)$. The frequency of each congenital defect varies with the species, breed, geographic location, season, and other environmental factors. The incidence of different kinds of congenital defect is reported to range from 2 to $3.5 \%$ of all births in calves, lambs and foals. The aim of this case report is to present the macroscopic, microscopic, and radiographic features of notomelia in a calf with two extra limbs, ectopia cordis and an ectopic lung grown over the backbone.

\section{Case Report}

A dead Korean native calf (Bos taurus coreanae) was removed from the uterus of a cow by cesarean section during late stages of pregnancy and submitted for pathological evaluation to the laboratory of

*Corresponding author

Tel: +82-63-270-4638, Fax: +82-63-270-3780

E-mail: bskims@jbnu.ac.kr 

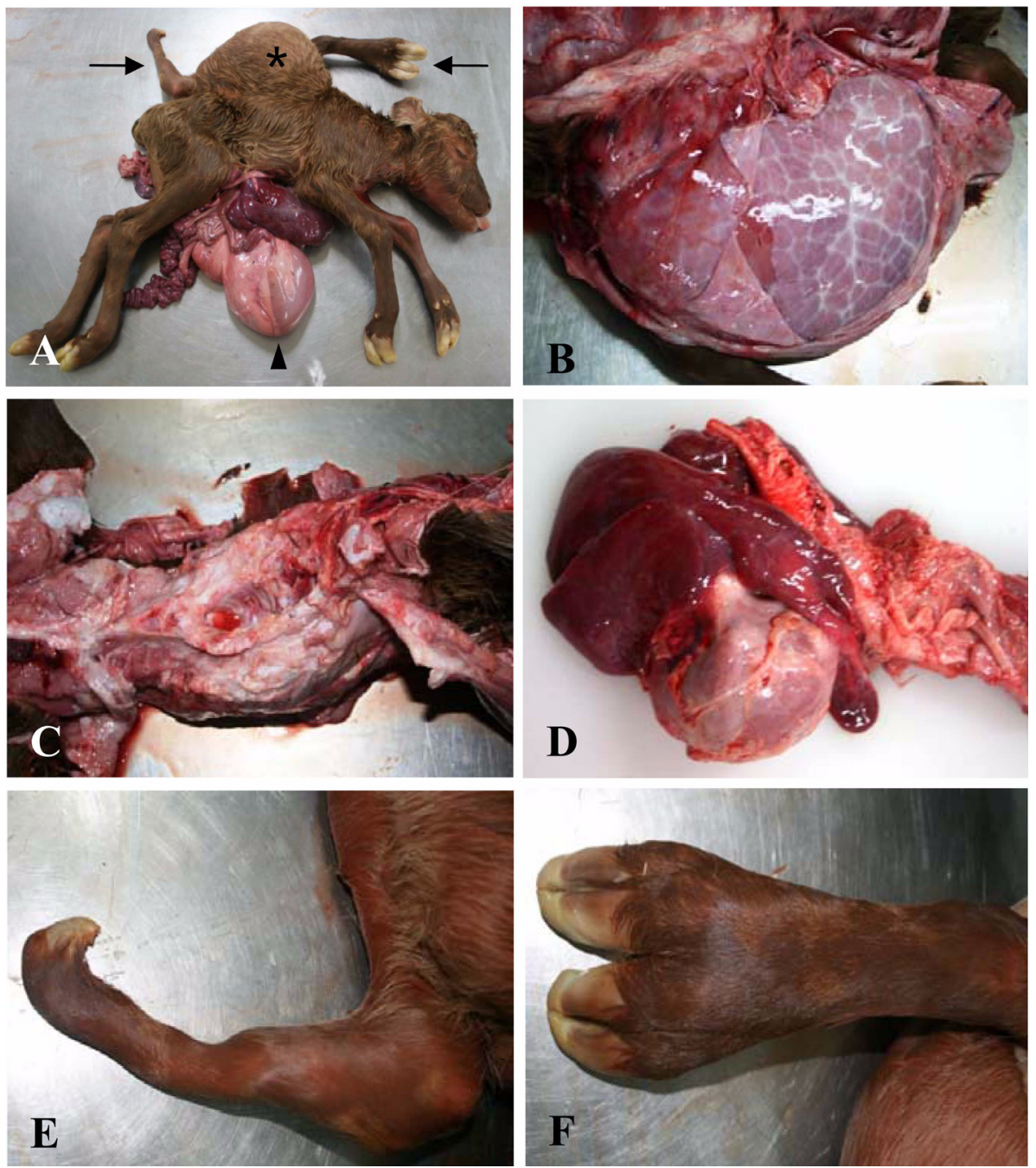

Fig. 1. Gross findings of calf. (A) Two extra abnormal limbs (arrows) originating laterally and separately from within the ectopic lung (asterisk), which grew over the middle of the backbone. Most abdominal organs (arrow head) were exposed to the outside, as the abdominal cavity was opened. (B) The ectopic lung tissue lacked lobulation. (C) The thoracic cavity was under developed and there was no lung tissue. (D) Abdominal ectopia cordis was attached to the liver. (E) The extra abnormal hindlimb was underdeveloped and had one hoof. (F) The extra forelimb was bifurcated at the fetlock joint and had four hooves.

Pathology in the College of Veterinary Medicine at Chonbuk National University with two extra limbs, a big mass on backbone and exposed internal organs. The calf was examined macroscopically, microscopically, and radiographically. For histopathological examination, collected tissue samples were fixed in $10 \%$ neutral buffered formalin. Fixed tissues were routinely processed for hematoxylin and eosin staining.

On physical examination, most of the internal organs were exposed through the opened abdominal cavity.
External features included an ectopic lung growing over the middle of the backbone, with two SELs originating from within it (Fig. 1A). The lung tissue was covered with normal haired skin, and lacked separate lobules (Fig. 1B). Thoracic cavity was under developed and there were no lung and heart (Fig. 1C). There was no connection between trachea and ectopic lung. There was an ectopia cordis attached to the liver in the abdominal cavity (Fig. 1D). Ectopia cordis was covered with pericardium. Regarding the two abnormal 

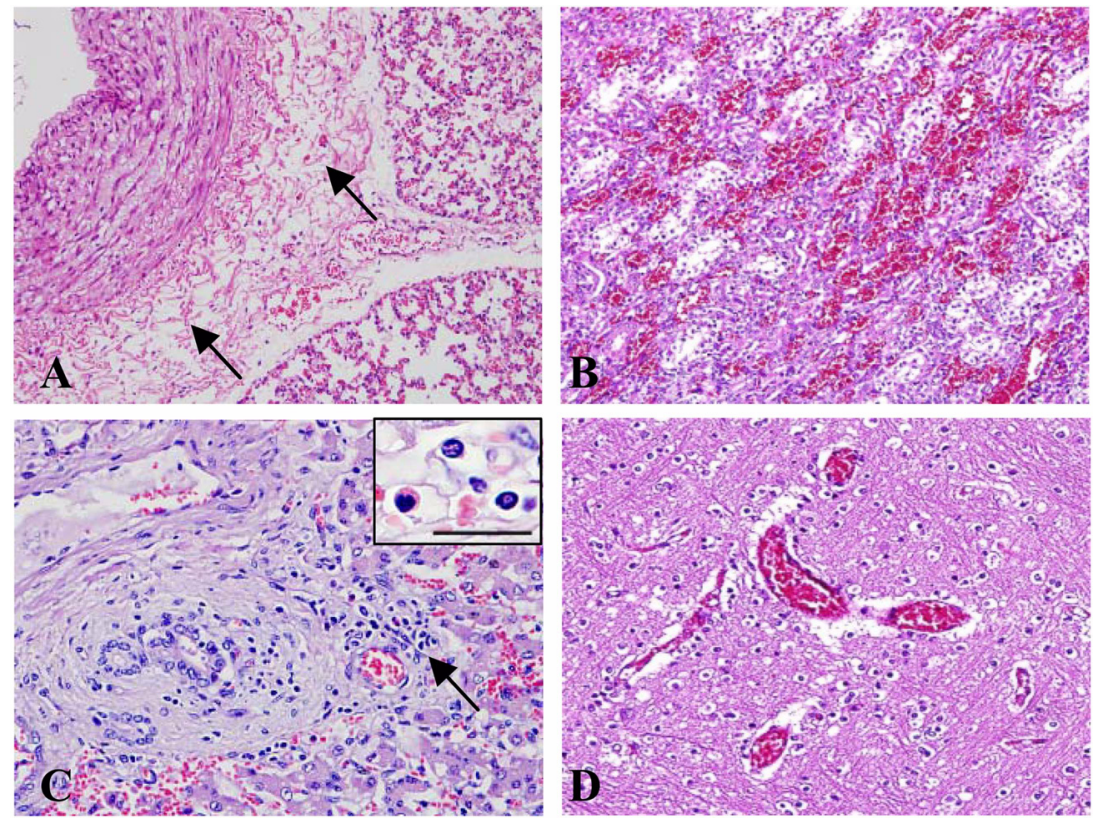

Fig. 2. Histopathological changes in different tissues. (A) Ectopic lung tissue had normal histological structure with collagen fiber dispersion and edema (arrows) around the artery. (B) Severe congestion of the renal medulla. (C) Inflammatory cells (arrow) including lymphocytes and eosinophils surrounding the bile duct at the hepatic portal tract (insert, Scale bar $=20$ $\mu \mathrm{m}$ ), indicating cholangitis. (D) Edema surrounding the blood vessels in the brain. H\&E stain, A, B, D: $\times 20$; C: $\times 40$.
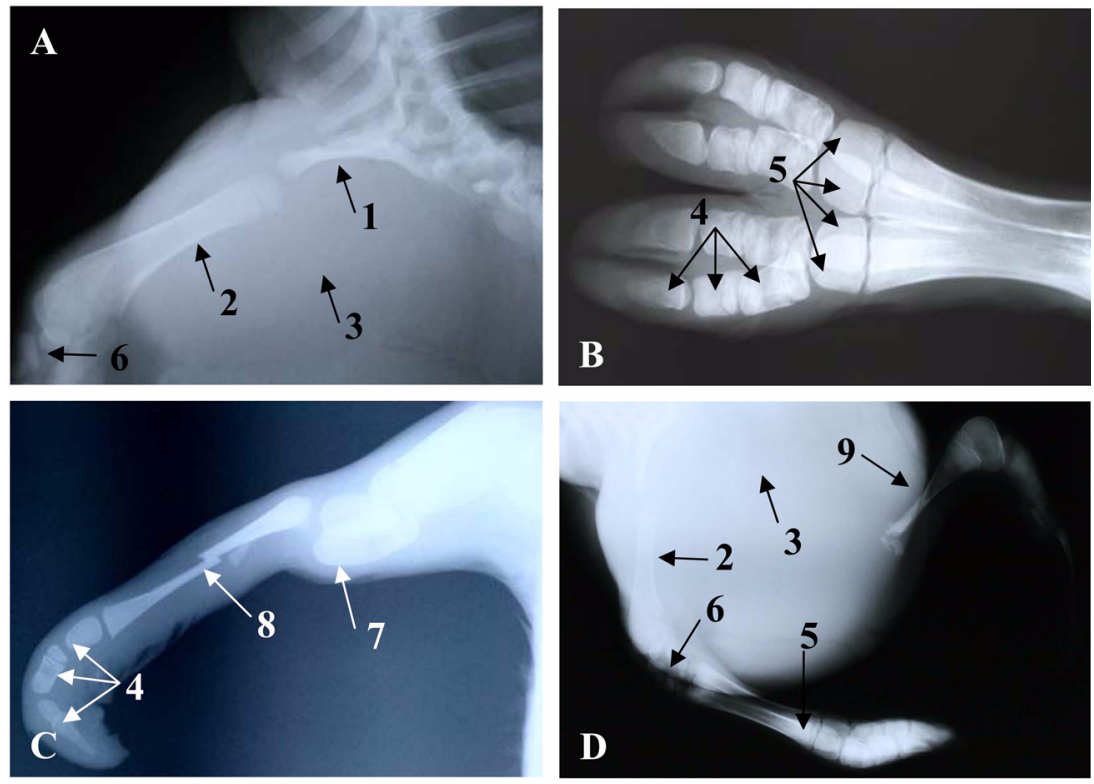

Fig. 3. Radiographic features of the calf. (A) Rudimentary humerus of the forelimb was attached to the thoracic spine. (B) Forelimb with four separate metacarpal bones and four hooves. (C) Hindlimb with an irregularly shaped femur, shortened tibia and fibula and a single metatarsal bone. (D) Two SELs were originated separately from within ectopic lung.

1: Rudimentary humerus, 2: Fused radio-ulna, 3: Ectopic lung, 4: Phalanges, 5: Metacarpal bones, 6: Carpal bones, 7: Tarsal bones, 8: Metatarsal bone, 9: Irregular shaped femur. 
legs, the hindlimb was underdeveloped and had one hoof (Fig. 1E); the forelimb was divided into two at the fetlock joint and had four hooves (Fig. 1F). The ectopic lung tissue had normal histologic structure, but with mild edema in the connective tissue around the bronchus and artery (Fig. 2A). Other histologic abnormalities observed were congestion of the renal medulla (Fig. 2B), infiltration of inflammatory cells (lymphocytes and eosinophils) around the hepatic portal tract (Fig. 2C), and edema surrounding blood vessels and neurons in the brain (Fig. 2D). The rudimentary humerus of the forelimb was attached to the thoracic spine due to absence of scapula, as seen radiographically (Fig. 3A). The forelimb consisted of one fused radio-ulna, ten carpal bones, four separated metacarpal bones, and hooves containing three phalanges each (Fig. 3B). The hindlimb consisted of an irregularlyshaped femur, shortened tibia and fibula, two tarsal bones, one metatarsal bone, and three phalanges (Fig. 3C). Two SELs were originated separately from within ectopic lung (Fig. 3D).

\section{Discussion}

During the embryonic stage of development, limbs arise as a condensation of cells from the lateral plate mesoderm and its ectodermal covering [2]. The limb primordia in amniotes develop from the wolffian ridges, which run along the lateral surface of the body [2]. The precise mechanism that regulates development of supernumerary limbs is not yet understood. Nonetheless, Mahapatra et al. [15] have reported vitamin A-induced multiplication of forelimbs and hindlimbs in tadpoles, thought to be due to lysosomal breakdown and disturbance of limb mesenchymal cells. The damaged primitive cartilage can break up into fragments, giving rise to duplicated limbs [12]. Two different surveys reported a $24 \%$ incidence of congenital musculoskeletal defects among the other congenital defects in cattle [9].

Heterotopic polymelia has been reported in humans, mice, chickens, calves, and lambs [6], although its etiology is not definitively known. This defect can result from defective genetics (transgenes, chromosomes), a genetic agent in the fetal environment, environmental agents (infections, toxins, fertilization techniques, management), or from an interaction of such factors [12]. Susceptibility to injurious genetic or environmental agents varies with the stage of fetal development, varies among species, and decreases with advancing fetal age. However, Schalles et al. [17] described calves with extra legs are caused by mistakes in development and not the genetic makeup of the individual or its parents. The pattern of SEL in this case is in full agreement with previous reports of similar cases in cattle $[1,3,6,8,9]$.

Among the most frequent congenital anomalies, limb malformations are found in both humans and animals, and they commonly affect the distal limb [11]. The presence of extra digits or toes, a condition called polydactyly, is the most common limb deformity in humans and is the consequence of disturbances in normal limb development. It can appear as an isolated condition or may be a part of a systemic syndrome [3]. At least two sets of genes are involved in the inheritance of polydactyly [17]. In this case, the calf's supernumerary ectopic forelimb was bifurcated at the fetlock joint and had four hooves, a polydactyly. Similar cases have been described in previous studies $[1,3]$. In this case the hindlimb was under developed and there was only one toe. Two toes might be fused together to produce only one toe, called syndactyly.

Ectopia cordis is a birth defect in which the heart is abnormally located anywhere outside the thoracic cavity. Ectopia cordis is subdivided into three types according to the site of displacement: cervical, pectoral, and abdominal [7]. In the present case, abdominal ectopia cordis was found in the abdominal cavity of the calf that was attached to the liver. The abdominal ectopia cordis is a very rare condition, though the cervical type is most frequently seen in cattle [7, 10]. The ectopia cordis in our case probably results from the fissure of the breastbone during development [18].

The most interesting features in this case were growth of an ectopic lung over the backbone and the absence of lungs in the thoracic cavity. The ectopic lung, which had no distinct lobules, appeared as a large pleura-covered mass protected by skin, but the lung tissue had normal histological structure except edema around the bronchus and artery. It has been previously reported that abnormal, nonfunctioning bovine lung tissue sometimes develops distant from the original lung site, such as in abdominal, thoracic or subcutaneous locations [5]. Bronchopulmonary abnormalities are hypothesized to arise from supernumerary lung buds that develop caudal to the normal lung buds and migrate caudally along with the growing esophagus. 
Although the prevalence of congenital lung malformations is unknown in animal species, they are generally thought to be rare [5]. Lucas et al. [14] described a case in which ectopic lung tissue arose from the head of a neonatal calf. To the best of our knowledge, our case may be the first report of ectopic lung tissue over the backbone with SELs and ectopia cordis of a newborn calf.

\section{Conclusion}

The present report describes a case of SEL with ectopic lung and ectopia cordis in a newborn calf. However, the etiology of the current case was not clearly demonstrated, and it is considered that various genetic and environmental factors might be related to the congenital anomalies in this calf.

\section{References}

1. Alam MR, Lee JI, Lee HB, Ko JJ, Lee KC, Kim NS. Supernumerary ectopic limbs in Korean indigenous cattle: four case reports. Vet Med (Praha) 2007, 52, 202-206.

2. Al-Qattan MM, Al-Thunayan A, De Cordier M, Nandagopal N, Pitkanen J. Classification of the mirror hand-multiple hand spectrum. J Hand Surg $\mathrm{Br}$ 1998, 23, 534-536.

3. Bähr C, Wittenberg K, Distl O. Case reportpolydactyly in a German Holstein calf. Dtsch Tierarztl Wochenschr 2003, 110, 333-335.

4. Camón J, Sabaté D, Franch J, López-Béjar MA, Pastor J, Rutllant J, Ordeig J, Degollada E, Verdú J. Associated multiple congenital malformations in domestic animals. Contribution of four cases. Zentralbl Veterinarmed A 1990, 37, 659-668.

5. Canpolat I, Eröksüz Y. Pulmonary Sequestration and Bronchogenic Cyst in a Calf. Firat Univ Vet J Health Sci 2007, 21, 281-284.

6. Carlson BM. Patten's Foundation of Embryology. 6th ed. pp. 393-412, McGraw-Hill, Philadelphia, 2003.

7. Hiraga T, Abe M. Eight calves of cervical ectopia cordis and their sternums. Nippon Juigaku Zasshi 1986,
48, 1199-1206.

8. Hiraga T, Abe M, Iwasa K, Takehana K, Tetsuka M. Seven-legged calf-dipygus with an extra foreleg at the pelvic region. Nippon Juigaku Zasshi 1989, 51, 1011-1015.

9. Kim CS, Yeon SC, Cho GH, Lee JH, Choi MC, Won CG, Kim JG, Lee SR. Polymelia with two extra forelimbs at the right scapular region in a male Korean native calf. J Vet Med Sci 2001, 63, 1161-1164.

10. Leipold HW, Dennis SM. Congenital defects affecting bovine reproduction. In: Morrow DA (ed.). Current Therapy in Theriogenology. pp. 410-441, Saunders, Philadelphia, 1980.

11. Leipold HW, Dennis SM. Cause, nature, effect and diagnosis of bovine congenital defects. Irish Vet News 1987, 9, 11-19.

12. Leipold HW, Huston K, Dennis SM. Bovine congenital defects. Adv Vet Sci Comp Med 1983, 27, 197-271.

13. Leopold H. Congenital defects of the musculoskeletal system. In: Greenough PR, Weaver AD (eds.). Lameness in Cattle. 3rd ed. pp. 79-86, Saunders, Philadelphia, 1997.

14. Lucas MJ, Johnson LW, Haley PJ. Ectopic lung tissue arising from the head of neonatal calf. Agri Practice 1984, 5, 45-47.

15. Mahapatra PK, Mohanty-Hejmadi P, Dutta SK. Polymelia in the tadpoles of Bufo melanostictus (Anura: Bufonidae). Curr Sci 2001, 80, 1447-1451.

16. Noh DH, Jeong WI, Lee CS, Jung CY, Chung JY, Jee YH, Do SH, An MY, Kwon OD, Williams BH, Jeong KS. Multiple congenital malformation in a Holstein calf. J Comp Pathol 2003, 129, 313-315.

17. Schalles RR, Leipold HW, McGraw RL. Congenital defects in cattle. In: Extension Beef Cattle Resource Committee (ed.). Beef Cattle Handbook. BCH-1900. University of Wisconsin-Extension, Cooperative Extension, Madison, 1999.

18. Schulze U, Kramer K, Hewicker-Trautwein $\mathbf{M}$, Haas L, Distl O. Case report: Ectopia cordis in a German Holstein calf. Dtsch Tierarztl Wochenschr 2006, 113, 281-284. 